\title{
Multiplicação in vitro de plantas juvenis de mamoeiro ${ }^{1}$
}

\author{
Francisco Ronaldo Vidal ${ }^{2}$, Josefa Diva Nogueira Diniz ${ }^{2}$, Fanuel Pereira da Silva ${ }^{2}$
}

\section{ABSTRACT}

In vitro micropropagation of young papaya plants

The seminiferous propagation of Carica papaya L. presents a mixture of genotypes with a strong influence on fruit production costs, quality and yield, prevailing due to the lack of efficient protocols for vegetative propagation. In this context, the tissue culture emerges as a promising alternative, because it can provide, to farmers, sex determination in seedlings, with a high quality standard and enough amounts to supply commercial demands in all seasons. This study aimed at developing an in vitro micropropagation protocol from young papaya material, in two experiments. In the first experiment, the explants were multiplied in vitro and the cytokinins BAP, $2 \mathrm{iP}$ and $\mathrm{KIN}$ were tested at the concentrations of $0.0 \mathrm{mg} \mathrm{L}^{-1}, 2.5 \mathrm{mg} \mathrm{L}^{-1}, 5.0 \mathrm{mg} \mathrm{L}^{-1}$ and $10.0 \mathrm{mg} \mathrm{L}^{-1}$, with the best results observed for $2 \mathrm{iP}$, especially at the $2.5 \mathrm{mg} \mathrm{L}^{-1}$ concentration. In the second one, the $2 \mathrm{iP}$ cytokinin was used at the concentrations of $0.0 \mathrm{mg} \mathrm{L}^{-1}, 1.0 \mathrm{mg} \mathrm{L}^{-1}$, $2.0 \mathrm{mg} \mathrm{L}^{-1}$ and $4.0 \mathrm{mg} \mathrm{L}^{-1}$, with and without $\mathrm{GA}_{3}\left(0.0 \mathrm{mg} \mathrm{L}^{-1}\right.$ and $1.0 \mathrm{mg} \mathrm{L}^{-1}$ ), with beneficial effects of $\mathrm{GA}_{3}$ observed in the multiplication process, especially when combined with $1.0 \mathrm{mg} \mathrm{L}^{-1}$ of $2 \mathrm{iP}$, with the best results for plants height, number of leaves and explants sprouting.

KEY-WORDS: Carica papaya L.; tissue culture; growth regulators.

\section{INTRODUÇÃO}

A propagação seminífera do mamoeiro resulta em problemas de disseminação de doenças e de variabilidade genética, decorrentes da polinização livre (Schmildt et al. 2007). Apesar dos problemas genéticos, principalmente quanto à herança do sexo, este método de propagação é utilizado devido à inexistência de protocolos eficientes de propagação vegetativa (Teixeira $\&$ Teixeira 2004).

O desenvolvimento de protocolos, utilizando-se técnicas de cultura de tecidos como a micropropagação, proporciona a multiplicação de plantas com

\section{RESUMO}

O método de propagação seminífera do mamoeiro (Carica papaya L.) apresenta uma mistura de genótipos com influência marcante nos custos de produção, qualidade e rendimento dos frutos, prevalecendo devido à inexistência de protocolos eficientes de propagação vegetativa. Neste contexto, a cultura de tecidos surge como uma alternativa promissora, pois poderá fornecer aos produtores mudas com sexo definido, alto padrão de qualidade e em quantidade suficiente para atender à demanda comercial, em qualquer época do ano. Este trabalho objetivou desenvolver um protocolo de multiplicação in vitro, a partir de material juvenil de mamoeiro, em dois experimentos. No primeiro, os explantes foram multiplicados in vitro, testando-se as citocininas $\mathrm{BAP}, 2 \mathrm{iP}$ e $\mathrm{CIN}$, nas concentrações de $0,0 \mathrm{mg} \mathrm{L}^{-1}, 2,5 \mathrm{mg} \mathrm{L}^{-1}, 5,0 \mathrm{mg} \mathrm{L}^{-1}$ e $10,0 \mathrm{mg} \mathrm{L}^{-1}$, com o melhor desenvolvimento sendo observado para $2 \mathrm{iP}$, sobretudo na concentração de $2,5 \mathrm{mg} \mathrm{L}^{-1}$. No segundo, foi utilizada a citocinina 2iP, nas concentrações de $0,0 \mathrm{mg} \mathrm{L}^{-1}, 1,0 \mathrm{mg} \mathrm{L}^{-1}, 2,0 \mathrm{mg} \mathrm{L}^{-1} \mathrm{e}$ $4,0 \mathrm{mg} \mathrm{L}^{-1}$, com e sem $\mathrm{GA}_{3}\left(0,0 \mathrm{mg} \mathrm{L}^{-1}\right.$ e $\left.1,0 \mathrm{mg} \mathrm{L}^{-1}\right)$, constatandose o efeito benéfico do $\mathrm{GA}_{3}$ na multiplicação, especialmente quando combinado com 1,0 $\mathrm{mg} \mathrm{L}^{-1}$ de $2 \mathrm{iP}$, sendo observados os melhores resultados para altura, número de folhas e brotações dos explantes.

PALAVRAS-CHAVE: Carica papaya L.; cultura de tecidos; reguladores de crescimento.

características agronômicas desejáveis, como híbridos e plantas hermafroditas com excelentes padrões de qualidade morfológica, sanitária e fisiológica, surgindo como uma alternativa promissora, pois esta técnica constitui-se em um recurso útil, na rápida formação de clones com características superiores (Schiavinato et al. 2008).

O sucesso do cultivo in vitro está diretamente relacionado com a manipulação isolada ou combinada de reguladores de crescimento. Segundo Melo et al. (2001), o cultivo in vitro sem reguladores de crescimento é quase impraticável, e a adição destes aos meios de cultivo desempenha a função de suprir 
prováveis deficiências endógenas de hormônios nos explantes.

Almeida et al. (2009), testando o efeito das citocininas BAP, CIN e 2iP, em Crossandra infundibulisformis Nees cv. Mona Wallhead, obtiveram maior percentagem de brotação com BAP, tendo 2iP apresentado o menor desempenho. Já Figueiredo et al. (2008), avaliando as citocininas 2iP, BAP e Zeatina, no estabelecimento in vitro de marmeleiro japonês [Chaenomelis japônica (Thunb.) Lindl. ex Spach cv. Andramig I], também obtiveram os melhores resultados com BAP, seguida por $2 \mathrm{iP}$. $\mathrm{Na}$ multiplicação in vitro de mandacaru (Cereus jamacaru P.DC.), a 2iP mostrou-se mais eficiente que BAP (Oliveira et al. 2008). Poucas diferenças foram encontradas por Furtado et al. (2007), no uso dos reguladores TDZ, BAP e CIN, na regeneração in vitro de amendoim (Arachis hipogaea L.).

Um dos reguladores de crescimento mais comumente utilizados na fase de multiplicação é o BAP (Fráguas et al. 2004), todavia, isto não significa que seja o ideal para todas as espécies. A propagação do mamoeiro cultivar Sunrise Solo mostrou-se mais promissora com a utilização de BAP na concentração de 1,0-2,0 $\mathrm{mg} \mathrm{L}^{-1}$ (Teixeira \& Teixeira 2004). Em trabalho com figueira (Ficus carica L.), Fráguas et al. (2004) verificaram que a concentração de $0,5 \mathrm{mg} \mathrm{L}^{-1}$ de cinetina resultou em taxa satisfatória de multiplicação, a partir de segmentos nodais. Em mandacaru, o 2iP, na concentração de $1,0 \mathrm{mg} \mathrm{L}^{-1}$, induziu o maior número de brotações, altura e peso seco dos explantes (Oliveira et al. 2008).

Dentre as giberelinas, o ácido giberélico $\left(\mathrm{GA}_{3}\right)$ é o mais importante comercialmente, todavia, o seu uso não é considerado essencial, na micropropagação, sendo requerido, às vezes, no auxílio da multiplicação de algumas espécies (Hartmann et al. 2007).

Segundo Gomes (1999), o uso de GA, nas concentrações de 1,0-6,0 mg L-1, favoreceu o desenvolvimento in vitro de brotações de moreira (Maclura tinctoria L.). Em madioquinha-salsa (Arracacia xanthorrhiza Bancroft), o aumento da concentração de $\mathrm{GA}_{3}$ trouxe incrementos significativos à altura média e máxima das brotações, concomitantemente ao aumento no tamanho dos calos propagados in vitro (Madeira et al. 2005).

A resposta morfogênica é fortemente influenciada pelo genótipo, sendo fundamental o aperfeiçoamento de protocolos de propagação para cada espécie. Por isto, objetivou-se, com este trabalho, desenvolver um protocolo de multiplicação in vitro, a partir de explantes juvenis de mamoeiro.

\section{MATERIAL E MÉTODOS}

Os experimentos foram conduzidos no Laboratório de Cultura de Tecidos e em telado pertencentes ao Departamento de Fitotecnia do Centro de Ciências Agrárias da Universidade Federal do Ceará, de fevereiro a outubro de 2009.

Plantas de mamoeiro (Carica papaya L.) do grupo Formosa cv. Tainung 01 foram obtidas a partir da semeadura em bandejas de 54 células. Quando atingiram, aproximadamente, de $10,0 \mathrm{~cm}$ a $15,0 \mathrm{~cm}$, foram transferidas para sacos de polietileno contendo uma mistura de esterco de galinha, areia grossa e areia vermelha, na proporção de 1:5:5, sendo mantidas em telado com retenção de $30 \%$ do fluxo de radiação solar. Aos dois meses do transplantio, foram coletadas as brotações novas (segmentos nodais) destas plantas, as quais foram estabelecidas, multiplicadas e mantidas in vitro, em meio MS (Murashige \& Skoog 1962) com 1,0 mg L $\mathrm{m}^{-1}$ de BAP e $0,5 \mathrm{mg} \mathrm{L}^{-1}$ de ANA, por até quatro subcultivos, sendo usadas nos experimentos de multiplicação.

$\mathrm{O} \mathrm{pH}$ dos meios de cultivo foi ajustado para 5,7 e autoclavado por 20 minutos, a $121^{\circ} \mathrm{C}$. Após a inoculação, os explantes foram mantidos em sala de crescimento, com temperatura média de $26^{\circ} \mathrm{C}$, fotoperíodo de 16 horas e intensidade luminosa em torno de $38,8 \mathrm{~W} \mathrm{~m}^{-2}$.

\section{Experimento 1: Diferentes concentrações de BAP,} 2iP e CIN, na multiplicação in vitro de mamoeiro

Os explantes foram inoculados em tubos de ensaio $(25,0 \mathrm{~mm} \times 150,0 \mathrm{~mm})$ contendo, aproximadamente, 10,0 mL de meio de cultura MS, acrescido de $0,5 \mathrm{mg} \mathrm{L}^{-1}$ de ANA e das citocininas BAP, CIN e 2iP, nas concentrações de $2,5 \mathrm{mg} \mathrm{L}^{-1}, 5,0 \mathrm{mg} \mathrm{L}^{-1} \mathrm{e}$ $10,0 \mathrm{mg} \mathrm{L}^{-1}$, isoladamente, além do tratamento testemunha (sem citocinina).

O modelo experimental foi o inteiramente casualizado, com 10 tratamentos e 30 explantes por tratamento (um explante por tubo), sendo realizada a análise de regressão para as concentrações das citocininas.

Aos 38 dias após a inoculação, foram avaliadas as seguintes variáveis: altura média dos explantes (cm), número de gemas emitidas por explante, 
número de folhas por explante e massa seca dos explantes $(\mathrm{g})$.

Experimento 2: Diferentes concentrações de $2 i P e$ $G A_{3}$, na multiplicação in vitro de mamoeiro

Os explantes retirados de plantas mantidas in vitro foram inoculados em tubos de ensaio $(25,0 \mathrm{~mm} \mathrm{x}$ $150,0 \mathrm{~mm}$ ) contendo, aproximadamente, $10,0 \mathrm{~mL}$ de meio de cultura MS, acrescido de $0,1 \mathrm{mg} \mathrm{L}^{-1}$ de ANA e diferentes concentrações de $2 \mathrm{iP}\left(0,0 \mathrm{mg} \mathrm{L}^{-1}\right.$, $1,0 \mathrm{mg} \mathrm{L}^{-1}, 2,0 \mathrm{mg} \mathrm{L}^{-1}$ e $4,0 \mathrm{mg} \mathrm{L}^{-1}$ ), com e sem $\mathrm{GA}_{3}$ $\left(0,0 \mathrm{mg} \mathrm{L}^{-1}\right.$ e $\left.1,0 \mathrm{mg} \mathrm{L}^{-1}\right)$.

O modelo experimental utilizado foi o inteiramente casualizado, em esquema fatorial $4 \times 2$, sendo o primeiro fator correspondente a três concentrações da citocinina $2 \mathrm{iP}$ e à testemunha e o segundo fator a presença e ausência do $\mathrm{GA}_{3}$, constituindo oito tratamentos, com 20 explantes por tratamento (um explante por tubo).

Aos 35 dias após a inoculação, foram avaliadas as seguintes variáveis: altura média dos explantes (cm), número de brotações emitidas por explante, número de folhas, massa seca dos explantes (g) e tamanho do calo formado, sendo medido o diâmetro da base dos calos e atribuídas as seguintes notas: 0 (sem calo); 1 (calo iniciando); 2 (calo medindo, aproximadamente, $0,5 \mathrm{~cm}$, na sua base); 3 (calo medindo, aproximadamente, $1,0 \mathrm{~cm}$, na sua base); e 4 (calo medindo, aproximadamente, $1,5 \mathrm{~cm}$, na sua base).

Os dados foram submetidos à análise de variância e de regressão. As médias dos fatores qualitativos foram comparadas utilizando-se o teste de Scott-Knott, a 5\%. Para os fatores quantitativos, os modelos de regressão foram escolhidos com base na significância dos coeficientes de regressão.

\section{RESULTADOS E DISCUSSÃO}

No primeiro experimento, verificou-se que, com o 2iP, os explantes apresentaram melhor desenvolvimento, comparativamente aos reguladores BAP e CIN, com a maior altura média $(3,2 \mathrm{~cm})$ sendo observada no tratamento com $2,5 \mathrm{mg} \mathrm{L}^{-1}$ de $2 \mathrm{iP}$, havendo uma redução, a partir desta concentração (Figura 1a).

Schuch et al. (2008), em mirtileiro (Vaccinium ashei Reade) cv. Climax, observaram a maior altura das plântulas (cerca de 1,8 cm) aos 60 dias, com $2,5 \mathrm{mg} \mathrm{L}^{-1} \mathrm{e} 5,0 \mathrm{mg} \mathrm{L}^{-1}$ de $2 \mathrm{iP}$, em relação à zeatina.
O maior número médio de gemas por explante foi observado na presença de $2 \mathrm{iP}$, sendo a concentração de 5,0 $\mathrm{mg} \mathrm{L}^{-1}$ a melhor, com média de 2,12 gemas (Figura 1b). Estes resultados concordam com os obtidos por Chuenboonngarm et al. (2001), em gardênia (Gardenia jasminoides Ellis), os quais obtiveram o maior número de gemas em concentrações similares de 2iP. Almeida et al. (2010), testando diferentes citocininas na multiplicação de mussaenda (Mussaenda erytrophylla) cv. Rosea, também obtiveram bons resultados com baixas concentrações de cinetina. De acordo com estudos realizados por Vieira et al. (2009), com cana-de-açúcar (Saccharum officinarum L.), o aumento nas concentrações dos reguladores de crescimento, no meio de cultura, não implica, necessariamente, no melhor desenvolvimento das brotações, havendo um limite sutil entre a indução e a inibição, o que é específico para cada espécie vegetal.

O número médio de folhas foi maior na presença de 2iP (Figura 1c), havendo diferença entre as concentrações testadas, com uma tendência de redução, quando a concentração foi aumentada para 10,0 $\mathrm{mg} \mathrm{L}^{-1}$. Quando utilizou-se BAP e CIN, verificou-se tendência de redução no número de folhas, com o aumento da concentração. Resultado semelhante foi constatado por Lima et al. (2007), trabalhando com hortelã verde (Menta viridis L.), para o qual não verificaram aumentos significativos no número de folhas, aumentando-se a concentração de BAP.

$\mathrm{O}$ efeito positivo da citocinina $2 \mathrm{iP}$ sobre a massa seca está ilustrado na Figura 1d, com maior valor $(0,95 \mathrm{~g})$ na concentração de $5,0 \mathrm{mg} \mathrm{L}^{-1}$, ao passo que CIN e BAP apresentaram maior massa seca na concentração de $2,5 \mathrm{mg} \mathrm{L}^{-1}(0,39 \mathrm{~g}$ e $0,48 \mathrm{~g}$, respectivamente), diminuindo com o acréscimo dos reguladores. Em mandacaru, Oliveira et al. (2008) também verificaram maior massa seca na presença de 2iP, comparativamente ao BAP.

No segundo experimento, observou-se maior altura média dos explantes no tratamento com $1,0 \mathrm{mg} \mathrm{L}^{-1}$ de 2iP, na presença de $1,0 \mathrm{mg} \mathrm{L}^{-1} \mathrm{de}_{\mathrm{GA}_{3}}$ (Figura 2a). Na ausência de 2iP, quando se acrescentou $\mathrm{GA}_{3}$, houve aumento significativo (de $1,3 \mathrm{~cm}$ para $3,0 \mathrm{~cm})$ no tamanho dos explantes. Estes resultados estão de acordo com os obtidos por Figueiredo et al. (2001), os quais, trabalhando com biribá (Rollinia mucosa Jacq. Baill), verificaram a importância do $\mathrm{GA}_{3}$ para o alongamento das brotações. Fráguas et 

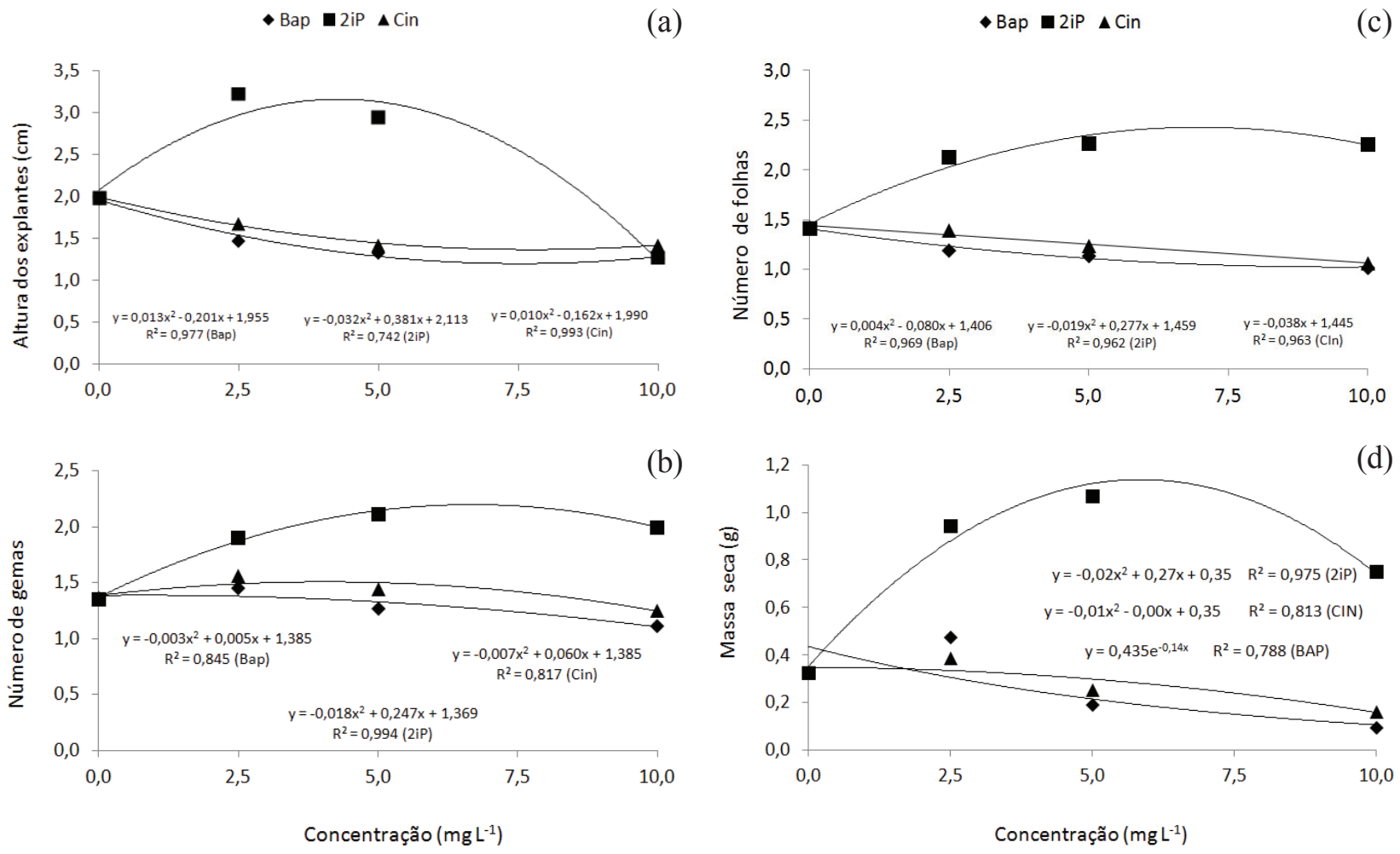

Figura 1. Altura média (a), número médio de gemas (b), número médio de folhas (c) e massa seca (d) dos explantes de mamoeiro (Carica papaya cv. Tainung 01), aos 38 dias de cultivo in vitro em meio MS com $0,5 \mathrm{mg} \mathrm{L}^{-1}$ de ANA e diferentes concentrações das citocininas BAP, 2iP e CIN (Fortaleza, CE, 2009). Dados originais transformados por $\mathrm{Y}=\sqrt{\mathrm{X}}+1,0$, para as variáveis número de gemas e número de folhas.

al. (2004), em experimento com figueira (F. carica), atribuíram o maior tamanho dos explantes, na presença de $\mathrm{GA}_{3}$, ao estiolamento.

O maior número médio de brotações emitidas por explante $(1,84)$ foi observado no tratamento com $\mathrm{GA}_{3}$ e $1,0 \mathrm{mg} \mathrm{L}{ }^{-1}$ de $2 \mathrm{iP}$, havendo uma redução, quando a concentração foi aumentada (Figura 2b). Este aumento no número de brotações emitidas, quando se adicionou $1,0 \mathrm{mg} \mathrm{L}^{-1}$ de 2iP, também foi observado por Furtado et al. (2007), em amendoinzeiro (Arachis hipogaea L.), para o qual os autores relatam que a adição de citocininas ao meio de cultura quebra a dominância apical e promove o controle de um programa complexo da expressão do gene na cultura do tecido, resultando na formação de brotações.

O menor tamanho dos calos foi verificado na ausência dos reguladores de crescimento (Figura 2c). No tratamento sem $2 \mathrm{iP}$, quando o $\mathrm{GA}_{3}$ foi acrescentado ao meio, verificou-se aumento significativo no tamanho dos calos formados. Porém, na presença de $2 \mathrm{iP}, \mathrm{o} \mathrm{GA}_{3}$ influenciou na redução do tamanho dos calos, apresentando diferença para a maior con- centração de $2 \mathrm{iP}\left(4,0 \mathrm{mg} \mathrm{L}^{-1}\right)$. Desta forma, deve-se utilizar o $\mathrm{GA}_{3}$ para reduzir a formação de calos que dificultam o processo de multiplicação in vitro, devido à interferência na conexão entre a parte aérea e o sistema radicular da planta.

Castillo (1991) relata que um calo basal de tamanho excessivo é indesejável, por ser potencial promotor de modificações genéticas e exaurir os nutrientes do meio de cultura, em detrimento da formação de folhas e raízes.

Segundo Nogueira et al. (2007), o efeito conjunto da citocinina exógena presente no meio nutritivo e a endógena do explante proporcionaram uma elevada concentração deste regulador, ocasionando diminuição na formação de calos em murici-pequeno (Byrsonima intermedia A. Juss). No entanto, Grattapaglia \& Machado (1998) indicaram que o aumento excessivo da concentração de reguladores de crescimento leva à formação de maior quantidade de calos.

A maior massa seca de explantes foi verificada na concentração de $2,0 \mathrm{mg} \mathrm{L}^{-1}$ de $2 \mathrm{iP}$, com e 

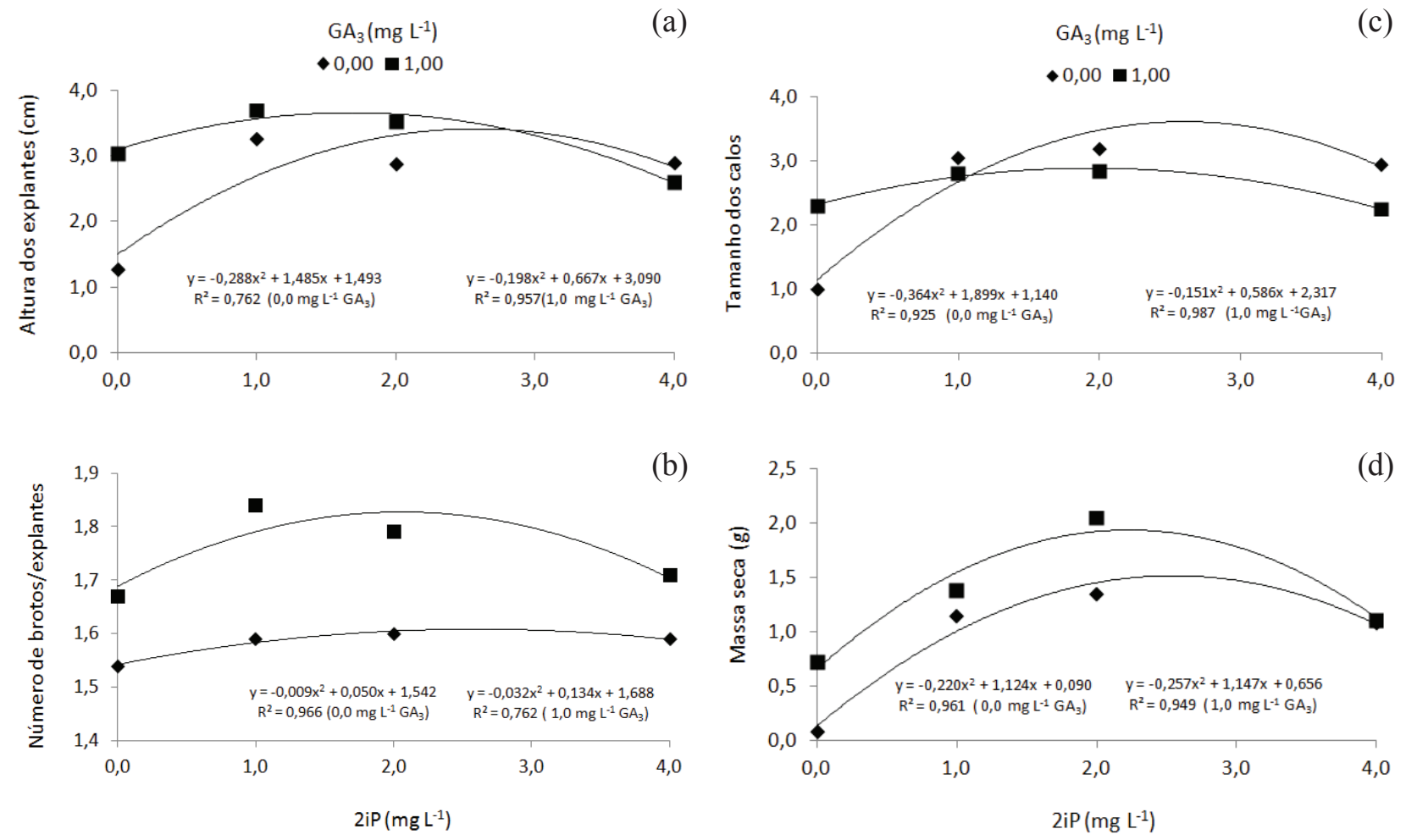

Figura 2. Altura média (a), número de brotos por explante (b), tamanho dos calos (c) e massa seca (d) dos explantes de mamoeiro (Carica papaya cv. Tainung 01), aos 38 dias de cultivo in vitro em meio MS com $0,5 \mathrm{mg} \mathrm{L}^{-1}$ de ANA e diferentes concentrações de $2 \mathrm{iP}\left(0,0 \mathrm{mg} \mathrm{L}^{-1}, 1,0 \mathrm{mg} \mathrm{L}^{-1}, 2,0 \mathrm{mg} \mathrm{L}^{-1}\right.$ e $\left.4,0 \mathrm{mg} \mathrm{L}^{-1}\right)$ e de $\mathrm{GA}_{3}\left(0,0 \mathrm{mg} \mathrm{L}^{-1}\right.$ e 1,0 mg L L $\left.^{-1}\right)$ (Fortaleza, CE, 2009).

sem GA 3 (Figura 2d). Quando se acrescentou o 2iP, houve aumento na massa seca, até a concentração

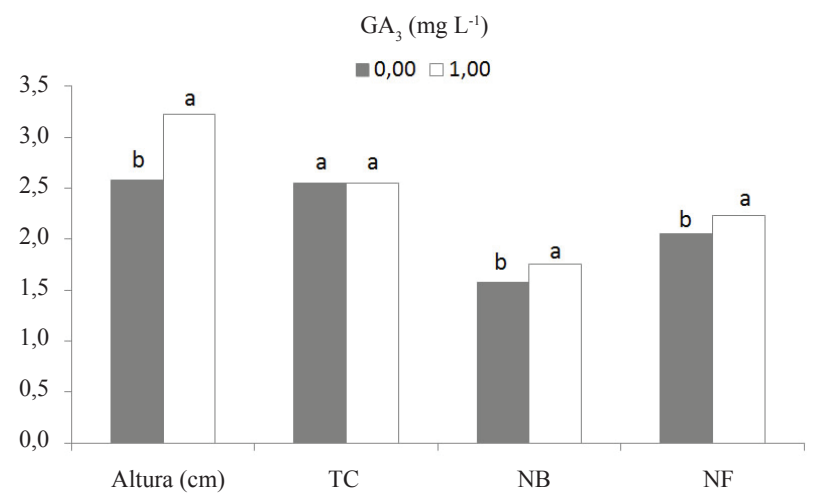

Figura 3. Altura média dos explantes, tamanho do calo (TC), número de brotações (NB) e número de folhas (NF) em explantes de mamoeiro (Carica papaya cv. Tainung 01 ), aos 35 dias de cultivo in vitro em meio MS com $0,1 \mathrm{mg} \mathrm{L}^{-1}$ de ANA, com e sem GA 3 (Fortaleza, CE, 2009). Letras distintas, no topo das colunas, em cada variável, indicam que as médias diferem entre si, pelo teste de Scott-Knott $(\mathrm{p} \leq 0,05)$. de 2,0 mg L-1, com e sem $\mathrm{GA}_{3}$, havendo uma redução, quando a concentração foi aumentada para 4,0 $\mathrm{mg} \mathrm{L}^{-1}$. Provavelmente, esta redução na massa seca seja devida à quantidade excessiva de $2 \mathrm{iP}$ no meio de cultivo, e os resultados estão de acordo com Santos (2008), que, trabalhando com abacaxizeiro ornamental (Ananas comousus) var. bracteatus, verificou que a concentração de $1,8 \mathrm{mg} \mathrm{L}^{-1}$ de $2 \mathrm{iP}$ promoveu o maior acúmulo de massa. Os dados também concordam com Diniz et al. (2003), os quais reportaram que não só a presença, mas o aumento nas concentrações de $\mathrm{GA}_{3}$, também resultava no aumento de massa seca em explantes de macela (Egletes viscosa $\mathrm{L}$. Less), cultivados in vitro.

$\mathrm{O} \mathrm{GA}_{3}$ influenciou, de forma significativa, no desenvolvimento dos explantes, apresentando maior crescimento em altura, número de brotações e número de folhas (Figura 3). $\mathrm{O} \mathrm{GA}_{3}$, associado ao $2 \mathrm{iP}$, contribuiu para a redução no tamanho dos calos, o que é desejável, uma vez que o objetivo é tentar diminuir sua produção, para facilitar as etapas posteriores do processo de multiplicação in vitro. 


\section{CONCLUSÕES}

1. Na multiplicação do mamoeiro, a partir de explantes retirados de plantas mantidas in vitro, o 2iP favoreceu a emissão de brotações mais desenvolvidas e com folhas normais, frente às demais citocininas testadas.

2. $\mathrm{O} \mathrm{GA}_{3}$ contribuiu para o melhor desenvolvimento dos explantes, quanto à altura, número de folhas e de brotações, especialmente quando combinado com 1,0 $\mathrm{mg} \mathrm{L}^{-1}$ de 2 iP.

\section{REFERÊNCIAS}

ALMEIDA, J. L.; DINIZ, J. D. N.; HERNANDEZ, F. F. F. Micropropagação de Crossandra infundibuliformis Ness cultivar 'Mona Wallhead'. Revista Brasileira de Horticultura Ornamental, Campinas, v. 14, n. 2, p. 115122, 2009.

ALMEIDA, J. L. et al. Propagação in vitro de mussaenda (Mussaenda erythrophylla cv. Rosea). Pesquisa Agropecuária Tropical, Goiânia, v. 40, n. 2, p. 206-212, 2010.

CASTILLO, R. Manejo e conservação de germoplasma de tuberosas andinas: informe final de consultoria para el Centro Internacional de La Papa (CIP). Quito: CIP, 1991.

CHUENBOONNGARM N.; CHAROONSOTE, S.; BHAMARAPRAVATI, S. Effect of BA and 2iP on shoot proliferation and somaclonal variation of Gardenia jasminoides Ellis in vitro culture. Science Asia, Bangkok, v. 27, n. 3, p. 137-141, 2001.

DINIZ, J. D. N. et al. Ácido giberélico $\left(\mathrm{GA}_{3}\right)$ e 6-Benzilaminopurina (BAP) no crescimento in vitro de macela [Egletes viscosa (L.) Less.]. Ciência e Agrotecnologia, Lavras, v. 27, n. 4, p. 934-938, 2003.

FIGUEIREDO, G. S. et al. Estabelecimento in vitro de marmeleiro japonês (Chaenomelis japonica) cv. Andramig I. In: CONGRESSO BRASILEIRO DE FRUTICULTURA, 20., 2008, Vitória. Disponível em: $<$ http://200.137.78.15/cd_XXCBF/paginas/Biotecnologia. pdf $>$. Acesso em: $11 \mathrm{dez} .2009$.

FIGUEREDO, S. F. L.; ALBARELLO, N.; VIANA, V. R. C. Micropropagation of Rollinia mucosa (Jacq.) Baill. In Vitro Cellular and Developmental Biology Plant, Wallingford, v. 37, n. 4, p. 471-475, 2001.

FRÁGUAS, C. B.; PASQUAL, M.; PEREIRA, A. R. Multiplicação in vitro de Ficus carica L.: efeito da cinetina e do ácido giberélico. Ciência e Agrotecnologia, Lavras, v. 28, n. 1, p. 49-55, 2004.
FURTADO, C. M. et al. Comparação da frequência de regeneração in vitro do amendoim (Arachis hipogaea L.), utilizando diferentes citocininas. Revista de Biologia e Ciência da Terra, Campina Grande, v. 1, n. 1, p. 51-58, 2007.

GOMES, G. A. C. Propagação in vitro de moreira (Maclura tinctoria L.). 1999. 91 f. Dissertação (Mestrado em Fisiologia Vegetal) - Universidade Federal de Lavras, Lavras, 1999.

GRATTAPAGLiA, D.; MACHADO, M. A. Micropropagação. In: TORRES, A. C.; CALDAS, L. S.; BUSO, J. A. Cultura de tecidos e transformação genética de plantas. Brasília, DF: Ministério da Agricultura, 1998. p. $183-260$.

HARTMANN, H. T. et al. Plant propagation: principles and practices. 7. ed. New Jersey: Prentice-Hall, 2007.

LIMA, C. S. M. et al. Influência de fitorreguladores no crescimento in vitro de partes aéreas de Mentha viridis. Revista Brasileira de Biociências, Porto Alegre, v. 5, supl. 2, p. 669-671, 2007.

MADEIRA, N. R. et al. Influência da concentração de $\mathrm{BAPe} \mathrm{AG}_{3}$ no desenvolvimento in vitro de mandioquinhasalsa. Horticultura Brasileira, Brasília, DF, v. 23, n. 4, p. 982-985, 2005.

MELO, B. et al. Efeito de ANA e AIB in vitro no enraizamento e crescimento da parte aérea de plântula de guarirobeira [Syagrus oleracea (Mart.) Becc.]. Bioscience, Bangalore, v. 17, n. 1, p. 49-59, 2001.

MURASHIGE, T.; SKOOG, F. A revised medium for rapid growth and bio assays with tobacco tissue culture. Physiologia Plantarum, Copenhagen, v. 15, n. 3, p. 437497, 1962.

NOGUEIRA, R. C. et al. Indução de calos em explantes foliares de murici-pequeno (Byrsonima intermedia A. Juss.). Ciência e Agrotecnologia, Lavras, v. 31, n. 2, p. 366-370, 2007.

OLIVEIRA, A. B. de; DINIZ, J. D. N.; ALMEIDA, J. L. Multiplicação e enraizamento in vitro do mandacaru (Cereus jamacaru P. DC.). Plant Cell Culture Micropropagation, Lavras, v. 4, n. 1, p. 48-54, 2008.

SANTOS, M. do D. M. dos. Micropropagação do abacaxizeiro ornamental (Ananas comousus var. bracteatus (Lindley) Coppens \& Leal) e a avaliação da fidelidade genotípica dos propágulos. 2008. $127 \mathrm{f}$. Dissertação (Mestrado em Botânica) - Universidade de Brasília, Brasília, DF, 2008.

SCHIAVINATO,Y. O. et al. Micropropagação de Anthurium plowmannii Croat. Plant Cell Culture \& Micropropagation, Lavras, v. 4, n. 1, p. 15-20, 2008. 
SCHMILDT, O.; SCHMILDT, E. R.; AMARAL, J. A. T. Cinetina e ANA na multiplicação in vitro de mamoeiro 'Tainung 01'. Scientia Agraria, Curitiba, v. 8, n. 1, p. 5560, 2007.

SCHUCH, M. W. et al. Micropropagação como técnica de rejuvenescimento em mirtilo (Vaccinium ashei Reade) cultivar Climax. Ciência e Agrotecnologia, Lavras, v. 32, n. 3, p. 814-820, 2008.
TEIXEIRA, M. T.; TEIXEIRA, S. L. Estabelecimento de segmentos apicais de mamoeiro in vitro. Revista Ceres, Viçosa, v. 51, n. 296, p. 477-483, 2004.

VIEIRA, R. A. et al. Diferentes concentrações de 6-benzilaminopurina e cinetina na micropropagação in vitro das variedades rb867515 e rb855156 de cana-deaçúcar. Campo Digital, Campo Mourão, v. 4, n. 1, p. 122126, 2009. 